\title{
Determination of trace level bromate and perchlorate in drinking water by ion chromatography with an evaporative preconcentration technique
}

\author{
Yongjian Liu ${ }^{a}$, Shifen $\mathrm{Mou}^{\mathrm{a}, *}$, Shawn Heberling ${ }^{\mathrm{b}}$ \\ ${ }^{a}$ Research Center for Eco-Environmental Sciences, Chinese Academy of Sciences, PO Box 2871, Beijing 100085, China \\ ${ }^{\mathrm{b}}$ Dionex Corporation, Sunnyvale, CA 94086, USA
}

\begin{abstract}
A simple sample preconcentration technique employing microwave-based evaporation for the determination of trace level bromate and perchlorate in drinking water with ion chromatography is presented. With a hydrophilic anion-exchange column and a sodium hydroxide eluent in linear gradient, bromate and perchlorate can be determined in one injection within 35 min. Prior to ion chromatographic analysis, the drinking water sample was treated with an OnGuard-Ag cartridge to remove the superfluous chloride and concentrated 20-fold using a PTFE beaker in a domestic microwave oven for 15 min. The recoveries of the anions ranged from $94.6 \%$ for $\mathrm{NO}_{2}^{-}$to $105.2 \%$ for $\mathrm{F}^{-}$. The detection limits for bromate, perchlorate, iodate and chlorate were $0.1,0.2,0.1$ and $0.2 \mu \mathrm{g} / 1$, respectively. The developed method is applicable for the quantitation of bromate and perchlorate in drinking water samples. (C) 2002 Elsevier Science B.V. All rights reserved.
\end{abstract}

Keywords: Water analysis; Sample handling; Bromate; Perchlorate; Inorganic anions

\section{Introduction}

During the 1970s it was discovered that disinfection of drinking water by chlorination produced carcinogens, such as trihalomethanes. Since then, ozonation has increasingly become a promising alternative to chlorination. However, during the oxidizing process, bromide can be oxidized to bromate, which presents a potential problem since bromide is naturally present in source water. As one of the disinfection byproducts (DBPs), bromate with a concentration above $0.05 \mu \mathrm{g} / 1$ in drinking water has been proved to be a potential carcinogenic substance by both the US Environmental Protection Agency (EPA) and the World Health Organisation

*Corresponding author. Fax: +86-10-6284-9239.

E-mail address: shifenm@mail.rcees.ac.cn (S. Mou).
(WHO) [1]. In the US, the occurrence of bromate and other DBPs in drinking water is currently being documented by the EPA through the comprehensive collection of data mandated by the Information Collection Rule [2].

Perchlorate is an environmental contaminant usually associated with the storage, manufacture, and testing of solid rocket engines, missiles and fireworks, which use ammonium perchlorate as an oxidizer [3]. It has recently been found in drinking water wells in areas where aerospace materials and munitions have been manufactured and tested [4]. Perchlorate is a health concern, as it interferes with the ability of the thyroid gland to produce thyroid hormones. Therefore, it has been added to the unregulated contaminant monitoring list of the EPA [5-7].

Because of health concerns, bromate and per- 
chlorate in drinking water have drawn the attention of regulatory agencies worldwide. Concentrations of bromate and perchlorate in drinking water are very low, and large amounts of chloride can interfere with the determination of bromate. Therefore, the establishment of new, rapid, sensitive and convenient method for the determination of trace levels of bromate and perchlorate is urgently needed.

Bromate determination is usually carried out by ion chromatography (IC) with conductivity detection, as also suggested by EPA method 300.1. The detection limit is in the range of 5-25 $\mu \mathrm{g} / 1$ [8-10], depending on chloride concentration. With a highcapacity column and large-volume direct injection, a method detection limit (MDL) of $1.73 \mu \mathrm{g} / 1$ can be obtained [11].

Bromate can also be determined by UV detection at $195 \mathrm{~nm}$ with an MDL of $6.51 \mu \mathrm{g} / 1$ [12]. Postcolumn derivatization IC has also been used to improve detection limits for bromate analysis with UV detection. With post-column addition of chlorpromazine, an MDL for bromate of $0.49 \mu \mathrm{g} / \mathrm{l}$ can be achieved [9]. When the derivatization reagents are fuchsin and $0.25 \% o$-dianisidine, the MDL is 0.1 $\mu \mathrm{g} / 1[13,14]$. When the excess bromide is under acidic conditions, the occurrence of oxyhalide species, such as bromate, iodate and chlorite can result in the formation of tribromide ion, which can be detected spectrophotometrically at $267 \mathrm{~nm}$. In addition, with large-volume injection, the MDL is less than $0.5 \mu \mathrm{g} / 1[15,16]$.

Apart from conductivity detection and post-column derivatization, ion chromatography-mass spectrometry (IC-MS) [17], inductively coupled plasma mass spectrometry (ICP-MS) [18], electrospray tandem mass spectrometry (MS-MS) [19], gas chromatography-mass spectrometry (GC-MS) [20] and "heart-cut" technology [21] can also be used to determine trace level bromate in drinking water. The MDL of ICP-MS is $0.45 \mu \mathrm{g} / 1$, while with IC-MS the lowest MDL of $0.05 \mu \mathrm{g} / 1$ can be obtained.

Though the post-column derivatization and MSbased detection techniques described above can all be used to achieve sub- $\mu \mathrm{g} / 1$ level detection limits, they each add considerable complexity, and in some cases significant cost, to the analytical method. In addition, few sample preconcentration techniques are used in these methods.

Perchlorate can be determined by several methods.
The most common method is IC, with a detection limit of $0.3-0.7 \mu \mathrm{g} / 1$ [22]. Perchlorate can also be determined using a modified carbon-paste electrode, however, the detection limit is only $50 \mu \mathrm{g} / 1$ and is not suitable for trace level determination of perchlorate in drinking water [23]. Electrospray ionization MS is a novel method for the determination of perchlorate in drinking water; after ion-pair extraction, a detection limit of $0.1 \mu \mathrm{g} / 1$ can be achieved [24]. However, the method is somewhat complex and the cost significant.

In this paper, we report on the development and application of a new sample preconcentration method with microwave-assisted evaporation. The method allows the simultaneous separation and determination of bromate and perchlorate in one injection with a high-capacity anion-exchange column that allows the use of large-volume injection and conductivity-based detection. Other anions, such as fluoride $\left(\mathrm{F}^{-}\right)$, chloride $\left(\mathrm{Cl}^{-}\right)$, nitrite $\left(\mathrm{NO}_{2}^{-}\right)$, nitrate $\left(\mathrm{NO}_{3}^{-}\right)$, iodate $\left(\mathrm{IO}_{3}^{-}\right)$and chlorate $\left(\mathrm{ClO}_{3}^{-}\right)$, were also simultaneously determined.

\section{Experimental}

\subsection{Chemicals}

All reagents used were of analytical-reagent grade unless specified. All solutions were prepared in 18.3 $\mathrm{M} \Omega$ water, obtained from a water purification system (Barnstead, USA). Fluoride, chloride, nitrite, nitrate, bromate, chlorate, iodate and perchlorate stock solutions $(1000 \mathrm{mg} / \mathrm{l})$ were prepared by dissolving the corresponding mass of salts in purified water. The stock solutions were stored in a refrigerator at $4{ }^{\circ} \mathrm{C}$ and were stable for at least 2 weeks. Standard solutions were prepared daily by serial dilution of the stock solution prior to use. The eluents were deionized water (A), $5 \mathrm{mmol} / \mathrm{l}$ sodium hydroxide (B) and $100 \mathrm{mmol} / 1$ sodium hydroxide $(\mathrm{C})$, which were run in a linear gradient at a flow-rate of $1.0 \mathrm{ml} / \mathrm{min}$. All determinations were performed at room temperature and all samples were injected in triplicate.

\subsection{Instruments}

A Dionex Model DX-500 ion chromatograph (Sunnyvale, CA, USA) equipped with a GP40 gra- 
dient pump and ED40 electrochemical detector in the conductivity mode, an IonPac AS16 analytical column $(250 \times 4 \mathrm{~mm})$ and an IonPac AG16 guard column $(50 \times 4 \mathrm{~mm})$, an IonPac MetPac CC-1 column $(50 \times 4 \mathrm{~mm})$ as a metal scrubber column, an ASRS-I $(4 \mathrm{~mm})$ micromembrane suppressor and a 150- $\mu$ l sample loop were used. Both instrument control and data collection were performed by a Dionex PeakNet 5.11 chromatography workstation. A common household microwave oven with five cooking levels (Philips, China) was also used. OnGuard-Ag cartridges were used to remove superfluous $\mathrm{Cl}^{-}$. All samples were filtered with $0.45-\mu \mathrm{m}$ filters (Autoscience, Tianjin, China).

\section{Results and discussion}

\subsection{Sample pretreatment}

The determined anions $\mathrm{F}^{-}, \mathrm{Cl}^{-}, \mathrm{NO}_{2}^{-}, \mathrm{NO}_{3}^{-}, \mathrm{IO}_{3}^{-}$, $\mathrm{ClO}_{3}^{-}, \mathrm{BrO}_{3}^{-}$and $\mathrm{ClO}_{4}^{-}$are all thermostable in aqueous solution at $100{ }^{\circ} \mathrm{C}$ which is the boiling point of water [25]. By virtue of this characteristic, all eight anions in aqueous solution can be concentrated by heating and evaporating the solution.

Microwave technology is a new method for sample pretreatment. The microwave oven heats samples from the inside to the outside. With its high efficiency and fast heating, microwave technology has many applications in different research fields [26,27]. In this experiment, to maintain anion thermostability, an aqueous solution of the eight anions was put into the oven and heated. The water of the solution evaporated, so that the eight anions were concentrated but their characters were unchanged. In addition, several samples could be concentrated together.

As we know, the character of the container is very important in microwave heating; metal or common plastic containers can not be used. In this experiment, three kinds of containers were chosen. They were $100-\mathrm{ml}$ polytetrafluoroethylene (PTFE), quartz and glass beakers. First, $20 \mathrm{ml}$ aqueous solution of the eight anions was added to each of the beakers which were then put in the microwave oven and heated for $15 \mathrm{~min}$ at mid-high level. The three beakers were then removed from the oven. The small volumes of solution left in the beakers were transferred to three 1.0-ml PTFE vials, which were filled to $1.0 \mathrm{ml}$ with deionized water. The concentrated solutions were analyzed and the results of the recoveries of the three containers are listed in Table 1.

From Table 1 we can see that the best recovery data were obtained using the PTFE beaker. All the recoveries of the eight anions were between 94 and $105 \%$, and 96.5 and $95.7 \%$ for $\mathrm{BrO}_{3}^{-}$and $\mathrm{ClO}_{4}^{-}$, respectively. The recovery data using the other two beakers were not quite as good as those using the PTFE beaker because during the heating process the solutions in the two beakers bubbled up more vigorously and overflowed, while the solution in the PTFE beaker boiled gently, and very little overflowed. Though the two 100-ml beakers were substituted by larger beakers to prevent spillage, more anions were adsorbed on the walls of the beakers, and the final results indicated that there was little difference between the recovery data of 100- and 200-ml beakers. Therefore, to obtain the best recovery data, the container for microwave concentration should be made of PTFE. In this experiment, a 20-ml solution of the eight anions could be concentrated 20 -fold with a conventional microwave oven in $15 \mathrm{~min}$ : the concentration technique did not influence the determination of the eight anions.

Of the eight anions, nitrite is a reductive, and perchlorate is a oxidant. Therefore, a further experiment was conducted to study the interaction between

Table 1

Recoveries using the three different beakers

\begin{tabular}{|c|c|c|c|c|c|c|c|c|}
\hline & \multicolumn{8}{|c|}{ Average recoveries $(\%, n=3)$} \\
\hline & $\begin{array}{l}\mathrm{F}^{-}, \\
1.5 \mathrm{mg} / 1\end{array}$ & $\begin{array}{l}\mathrm{IO}_{3}^{-}, \\
10 \mathrm{mg} / 1\end{array}$ & $\begin{array}{l}\mathrm{BrO}_{3}^{-}, \\
10 \mathrm{mg} / 1\end{array}$ & $\begin{array}{l}\mathrm{Cl}^{-}, \\
1.5 \mathrm{mg} / 1\end{array}$ & $\begin{array}{l}\mathrm{NO}_{2}^{-} \\
5 \mathrm{mg} / 1\end{array}$ & $\begin{array}{l}\mathrm{NO}_{3}^{-}, \\
5 \mathrm{mg} / 1\end{array}$ & $\begin{array}{l}\mathrm{ClO}_{3}^{-}, \\
10 \mathrm{mg} / 1\end{array}$ & $\begin{array}{l}\mathrm{ClO}_{4}^{-}, \\
10 \mathrm{mg} / \mathrm{l}\end{array}$ \\
\hline Glass beaker & 120.1 & 80.1 & 91.0 & 89.2 & 87.3 & 90.6 & 89.1 & 88.8 \\
\hline Quartz beaker & 114.2 & 91.4 & 90.6 & 91.7 & 90.3 & 94.7 & 90.9 & 90.6 \\
\hline PTFE beaker & 105.2 & 96.1 & 96.5 & 103.3 & 94.6 & 98.5 & 96.7 & 95.7 \\
\hline
\end{tabular}


the two anions during the concentration process. A solution of $10 \mathrm{mg} / 1$ nitrite and $10 \mathrm{mg} / 1$ perchlorate was concentrated 10-fold using the microwave oven. The recoveries for nitrite and perchlorate were 92.3 and $103.2 \%$, respectively. In addition, no nitrate peak found in the chromatogram. The results indicated that there was no interaction between nitrite and perchlorate in the concentration process.

As we know, the concentration of $\mathrm{Cl}^{-}$in drinking water is very high. In Beijing's drinking water, it is $\sim 20 \mathrm{mg} / \mathrm{l}$. However, the concentration of $\mathrm{BrO}_{3}^{-}$in drinking water is very low, maybe at a sub- $\mu \mathrm{g} / 1$ level. When the concentrated sample is determined, the peak of $\mathrm{BrO}_{3}^{-}$may be completely covered by the large $\mathrm{Cl}^{-}$peak. Therefore, in order to determine trace levels of $\mathrm{BrO}_{3}^{-}$in drinking water, the sample must be pretreated before concentration in order to remove the superfluous $\mathrm{Cl}^{-}$. A Dionex OnGuard-Ag cartridge is used to remove $\mathrm{Cl}^{-}$and other halides, such as $\mathrm{Br}^{-}$and $\mathrm{I}^{-}$, from sample matrices. Its capacity for $\mathrm{Cl}^{-}$is more than $50 \mathrm{mg} /$ cartridge. In this experiment, a 30-ml drinking water sample was pretreated with a cartridge; the $\mathrm{Cl}^{-}$content was $\sim 600 \mu \mathrm{g}$ which was far less than the capacity of the cartridge. With sample pretreatment, almost all the $\mathrm{Cl}^{-}$in the sample could be removed. During the pretreatment process, bromate in the sample is not affected by the $\mathrm{Ag}$ cartridge [28]. After sample pretreatment, the 20-ml sample was concentrated using the microwave oven and made up to $1.0 \mathrm{ml}$ with deionized water. Then the concentrated sample was filtered and determined.

In order to prevent the leached silver from the OnGuard-Ag cartridge reaching the guard and analytical columns, a chelator column (MetPac CC-1) was introduced between the injection valve and the guard column. The column removes not only the silver but also other cations which may blemish the analytical column.

After sample pretreatment, concentration and filtration, the recoveries of $\mathrm{F}^{-}, \mathrm{NO}_{2}^{-}$and $\mathrm{NO}_{3}^{-}$were between 90.1 and $95.4 \%$. The recoveries of the DBPs of interest and perchlorate are listed in Table 2.

\subsection{Optimization of chromatographic parameters}

The Dionex AS16 analytical column is a highcapacity, hydroxide-selective anion-exchange column designed for the separation of polarizable anions including perchlorate in a variety of sample matrices. Because of very low hydrophobicity, bromate can be eluted easily.

The hydrophobicity and polarity of perchlorate are much higher than those of bromate. In order to simultaneously determine bromate and perchlorate, the eluent must be run in a linear gradient. At first, the eluent consisted of $\mathrm{A}-\mathrm{B}(61: 39)$ for $10 \mathrm{~min}$, then changed to A-B (51:49) over $9 \mathrm{~min}$, to $\mathrm{A}-\mathrm{B}-\mathrm{C}$ (37:69:2) over $3.5 \mathrm{~min}$, and to $100 \% \mathrm{C}$ for $1 \mathrm{~min}$, held for $6.5 \mathrm{~min}$, followed by a linear gradient to A-B (61:39) over 5 min. From Fig. 1, we can see that $\mathrm{BrO}_{3}^{-}$can be adequately separated with $\mathrm{Cl}^{-}$, and all eight anions can be determined in $35 \mathrm{~min}$.

Because of the high concentration of $\mathrm{Cl}^{-}$and the very low concentration of $\mathrm{BrO}_{3}^{-}$in the drinking water, it was important to determine the lowest $\mathrm{BrO}_{3}^{-}: \mathrm{Cl}^{-}$ratio that can ensure the determination of $\mathrm{BrO}_{3}^{-}$. As shown in Fig. 2, the results indicated that $\mathrm{BrO}_{3}^{-}$could be accurately determined when the ratio was 1:4000, and the RSD $(n=7)$ was less than $10 \%$. In addition, after pretreatment with the OnGuard-Ag cartridge, the concentration of $\mathrm{Cl}^{-}$was greatly decreased, so that it was very low even in the concentrated sample. Though the concentration of $\mathrm{BrO}_{3}^{-}$in the concentrated sample was extremely low, $\mathrm{Cl}^{-}$would not interfere in its determination.

Similarly $\mathrm{ClO}_{4}^{-}$could also be determined, since the high concentration of $\mathrm{Cl}^{-}$was almost completely removed by the cartridge.

Direct large sample loop injection has been used to determine $\mu \mathrm{g} / 1$ level anions, including $\mathrm{BrO}_{3}^{-}$, in

Table 2

Recoveries of the anions of interest treated with OnGuard-Ag cartridge

\begin{tabular}{lllll}
\hline & $\mathrm{IO}_{3}^{-}$ & $\mathrm{BrO}_{3}^{-}$ & $\mathrm{ClO}_{3}^{-}$ & $\mathrm{ClO}_{4}^{-}$ \\
\hline Determination concentrations $(\mathrm{mg} / \mathrm{l})$ & 10 & 10 & 10 & 10 \\
Average recoveries $(\%, n=3)$ & 95.3 & 97.1 & 96.6 & 95.7 \\
\hline
\end{tabular}




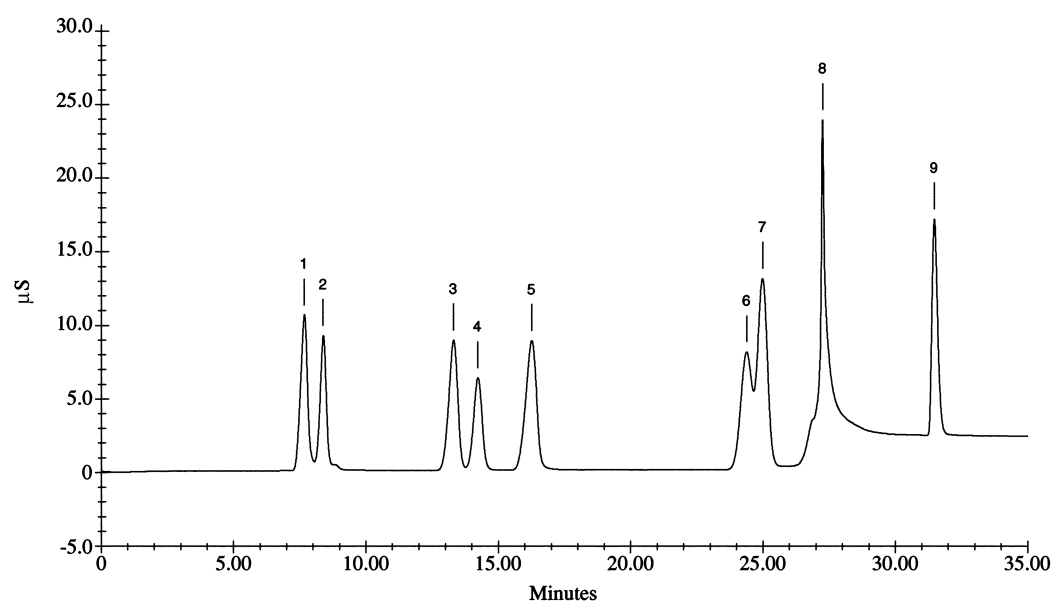

Fig. 1. Standard chromatogram of the eight anions. 1: Fluoride $(1.5 \mathrm{mg} / 1) ; 2$ : iodate $(10 \mathrm{mg} / 1) ; 3:$ bromate $(10 \mathrm{mg} / 1) ; 4:$ chloride $(1.5$ $\mathrm{mg} / 1)$; 5: nitrite $(5 \mathrm{mg} / 1) ; 6$ : nitrate $(5 \mathrm{mg} / 1) ; 7$ : chlorate $(10 \mathrm{mg} / 1) ; 8$ : system peak; 9: perchlorate $(10 \mathrm{mg} / 1)$.

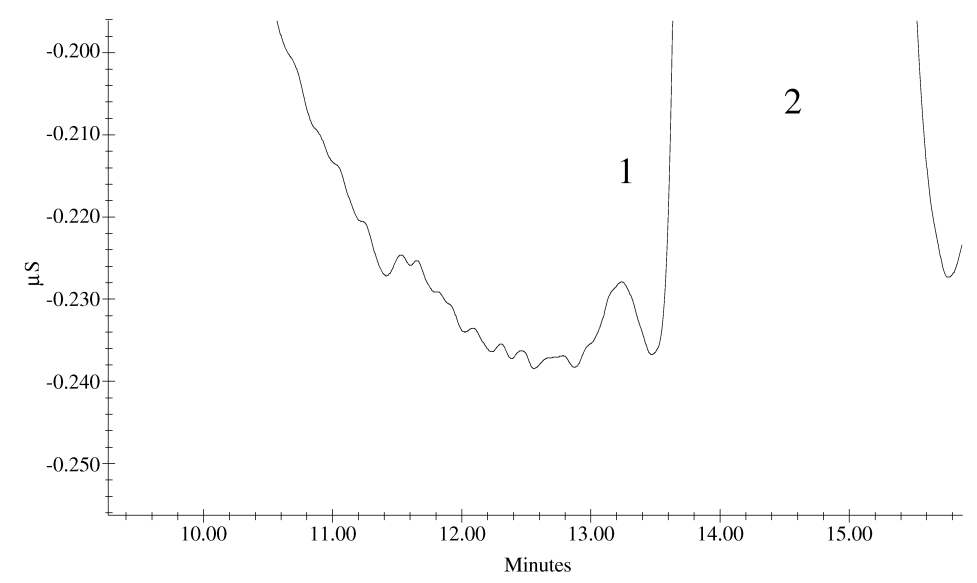

Fig. 2. Chromatogram of $\mathrm{BrO}_{3}^{-}$and $\mathrm{Cl}^{-}$. 1: Bromate $(0.005 \mathrm{mg} / 1) ; 2$ : chloride $(20 \mathrm{mg} / 1)$.

drinking water [11]. In this experiment, after sample concentration, as the volume of the sample was only $1.0 \mathrm{ml}$, the volume of the sample loop could not be too large. Therefore, a $150-\mu l$ sample loop was employed in the experiments.

\subsection{Detection limits}

The detection limits and the linear ranges of the eight anions are listed in Table 3. The results indicate that with the concentration technique and

Table 3

Detection limits and linear ranges of the eight anions with $150-\mu l$ sample loop and concentration technique

\begin{tabular}{lllllllll}
\hline & $\mathrm{F}^{-}$ & $\mathrm{IO}_{3}^{-}$ & $\mathrm{BrO}_{3}^{-}$ & $\mathrm{Cl}^{-}$ & $\mathrm{NO}_{2}^{-}$ & $\mathrm{NO}_{3}^{-}$ & $\mathrm{ClO}_{3}^{-}$ & $\mathrm{ClO}_{4}^{-}$ \\
\hline Detection limits ${ }^{\mathrm{a}}(\mu \mathrm{g} / \mathrm{l})$ & 0.14 & 0.11 & 0.10 & 0.32 & 0.11 & 0.36 & 0.21 & 0.20 \\
Concentration range $(\mu \mathrm{g} / 1)$ & $0.14-200$ & $0.11-25$ & $0.10-25$ & $0.32-200$ & $0.11-250$ & $0.36-300$ & $0.21-25$ & $0.20-25$ \\
Correlation coefficient $(r)$ & 0.9991 & 0.9992 & 0.9994 & 0.9993 & 0.9996 & 0.9990 & 0.9991 & 0.9996 \\
\hline
\end{tabular}

\footnotetext{
${ }^{\text {a }}$ Calculated as three times baseline noise.
} 


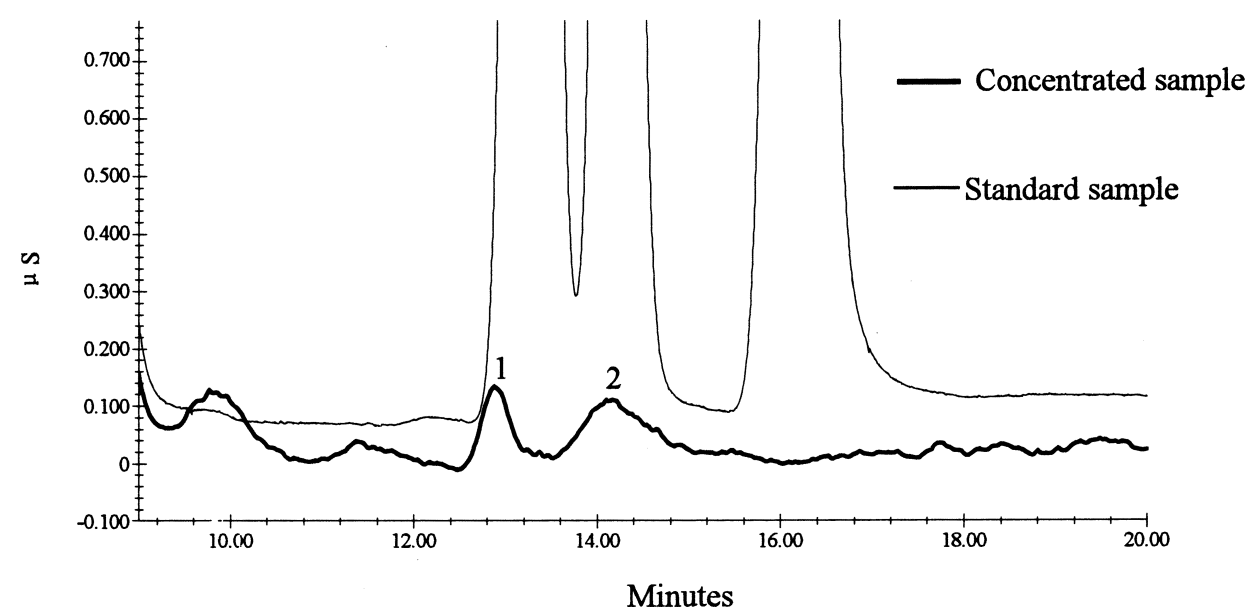

Fig. 3. Chromatograms of $\mathrm{BrO}_{3}^{-}$in concentrated drinking water sample and standard solution. 1: Bromate (0.58 $\left.\mu \mathrm{g} / 1\right)$; 2: chloride (1.02 $\mu \mathrm{g} / 1)$.

$150-\mu l$ sample loop, all the detection limits of the eight anions are at the ng/l level. The linear ranges of the eight anions are over the typical concentration ranges for the analytes in real drinking water.

\subsection{Application to real drinking water samples}

The described method has been applied to the determination of bromate, perchlorate and other DBPs and anions in Beijing's drinking water.
From Fig. 3, we can see that in the 20-fold concentrated sample, the content of $\mathrm{Cl}^{-}$was very low: the calculated result indicated that $99.99 \%$ of $\mathrm{Cl}^{-}$was removed from the sample. There is a small peak of bromate in the concentrated chromatogram.

From Fig. 4 it can be seen that there is a small peak of perchlorate in the 20-fold concentrated drinking water sample. The concentrations of bromate and perchlorate in the drinking water samples of Haidian and Chaoyang districts (the two largest

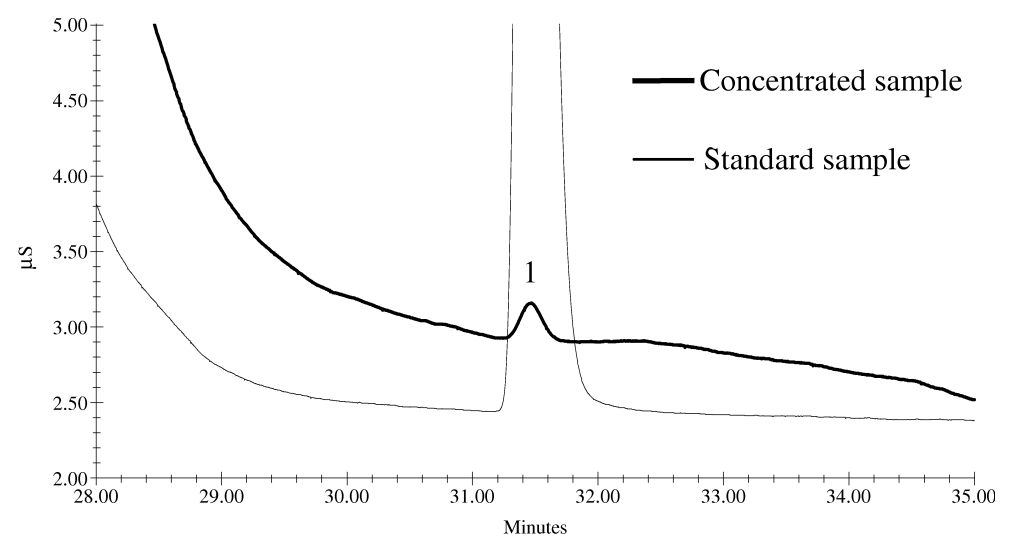

Fig. 4. Chromatograms of $\mathrm{ClO}_{4}^{-}$in concentrated drinking water sample and standard solution. 1: Perchlorate $(0.79 \mu \mathrm{g} / 1)$. 
Table 4

Concentrations of bromate and perchlorate in Beijing's drinking water

\begin{tabular}{lllll}
\hline & Samples & & & \\
\cline { 2 - 5 } & Haidian-1 & Haidian-2 & Chaoyang-1 & Chaoyang-2 \\
\hline Bromate $(\mu \mathrm{g} / 1)$ & 0.58 & $\mathrm{ND}^{\mathrm{a}}$ & ND & ND \\
Perchlorate $(\mu \mathrm{g} / 1)$ & 0.79 & ND & ND & ND \\
\hline
\end{tabular}

${ }^{\mathrm{a}}$ Not detected.

districts in Beijing) are listed in Table 4. In the four samples, only in one sample was very little bromate and perchlorate found.

\section{Conclusion}

A simple and convenient method for the preconcentration and determination of ng/l level oxyhalides in real drinking water was developed. The method allows the simultaneous determination of bromate and perchlorate with a single injection. With a household microwave oven, the drinking water sample can be concentrated 20 -fold in 15 min and excellent recoveries (95.3-96.7\%) can be obtained for these oxyhalides. With direct injection, the detection limits of the four oxyhalides are at the $\mathrm{ng} / \mathrm{l}$ level. The method is linear for the oxyhalides over the typical concentration ranges expected for these analytes in drinking water, and it is applicable for the determination of trace level oxyhalides in real world drinking water samples.

\section{References}

[1] Y. Kurokawa, A. Mackawa, M. Takahashi, Y. Hayashi, Environ. Health Perspect. 87 (1990) 309.

[2] Fed. Reg. 61 (1996) 24354

[3] E.T. Urbansky, M.R. Schock, J. Environ. Manage. 56 (1999) 79.

[4] Perchlorate in California Drinking Water, California Department of Health Services, September 1997.

[5] Fed. Reg. 63 (1998) 10274

[6] Drinking Water Contaminant List, GPO, Washington, DC, 1998, EPA Document No. 815-F-98-002.
[7] Correspondence from Joan S. Dollarhide, National Center for Environmental Assessment, Office of Research and Development, to Mike Girrard, Chairman, Perchlorate Study Group, EPA, 1995.

[8] U. Von Gunten, J. Hoigne, Environ. Sci. Technol. 28 (1994) 1234.

[9] B.D. Walters, G. Gordon, B. Bubnis, Anal. Chem. 69 (1997) 4275.

[10] R.J. Joyce, H.S. Dhillon, J. Chromatogr. A 671 (1994) 165.

[11] L.K. Jackson, R.J. Joyce, M. Laikhtman, P.E. Jackson, J. Chromatogr. A 829 (1998) 187.

[12] D.P. Hautman, M. Bolyard, J. Chromatogr. 602 (1992) 65.

[13] M. Achilli, L. Romele, J. Chromatogr. A 847 (1999) 271.

[14] H.P. Wagner, B.V. Pepich, D.P. Hautman, D.J. Munch, J. Chromatogr. A 850 (1999) 119.

[15] H.S. Weinberg, H. Yamada, Anal. Chem. 70 (1998) 1.

[16] M. Yamanaka, T. Sakai, H. Kumagai, Y. Inoue, J. Chromatogr. A 789 (1997) 2059.

[17] L. Charles, D. Pepin, Anal. Chem. 70 (1998) 353.

[18] M. Yamanaka, T. Sakai, H. Kumagai, Y. Inoue, J. Chromatogr. A 789 (1997) 259.

[19] L. Charles, D. Pepin, B. Casetta, Anal. Chem. 68 (1996) 2554.

[20] M.L. Magnuson, Anal. Chim. Acta 377 (1998) 53.

[21] Y. Huang, S.F. Mou, Y. Yan, J. Liq. Chromatogr. Relat. Technol. 22 (1999) 2235.

[22] P.E. Jackson, M. Laikhtman, J.S. Rohrer, J. Chromatogr. A 850 (1999) 131.

[23] C.G. Neuhold, K. Kalcher, X. Cai, G. Raber, Anal. Lett. 29 (1996) 1685.

[24] M.L. Magnuson, E.T. Urbansky, C.A. Kelty, Anal. Chem. 72 (2000) 25.

[25] R.C. Weast, M.J. Astle, in: CRC Handbook of Chemistry and Physics, 59th ed., CRC Press, 1978-1979, p. B91.

[26] H.M. Kingston, L.B. Jassie, Introduction To Microwave Sample Preparation: Theory and Practice, American Chemical Society, Washington, DC, 1988.

[27] F.I. Onuska, K.A. Terry, Chromatographia 36 (1993) 191.

[28] H. Weinberg, J. Chromatogr. A 671 (1994) 141. 